(C) 2016, Elsevier. Licensed under the Creative Commons Attribution-NonCommercial-NoDerivatives 4.0 International http://creativecommons.org/licenses/by-nc-nd/4.0/

\title{
Recent Advances in Explaining Hedge Fund Returns: Implicit Factors and Exposures
}

\author{
Dimitrios Stafylas ${ }^{1}$ \\ Keith Anderson ${ }^{2 *}$ \\ Moshfique Uddin ${ }^{3}$
}

\begin{abstract}
We survey articles covering how hedge funds returns are explained, using largely nonlinear multifactor models that examine the non-linear pay-offs and exposures of hedge funds. We provide an integrated view of the implicit factor and statistical factor models that are largely able to explain the hedge fund return-generating process. We present their evolution through time by discussing pioneering studies that made a significant contribution to knowledge, and also recent innovative studies that examine hedge funds exposures using advanced econometric methods. This is the first review that analyzes very recent studies that explain a large part of hedge fund variation. We conclude by presenting some gaps for future research.
\end{abstract}

Keywords: hedge fund performance; implicit factors; statistical factors; linear and non-linear multi-factor models; alpha and beta returns

\footnotetext{
${ }^{1}$ Aston Business School, Aston University, Birmingham B4 7ET, England.

2 The York Management School, University of York, Freboys Lane, Heslington, York YO10 5GD, England. Tel. +44 1904 325001. Email keith.anderson@york.ac.uk

${ }^{3}$ Leeds University Business School, Maurice Keyworth Building, University of Leeds, Moorland Road, Leeds LS6 1AN, England.
} 


\section{Introduction}

A large and growing body of literature has investigated hedge fund performance attribution through the use of implicit or statistical factor models (e.g. Billio, Getmansky and Pelizzon, 2012; Akay, Senyuz, and Yoldas, 2013; O’Doherty, Savin, and Tiwari, 2015). Investors want to know what is behind hedge fund return variation and what to expect from different hedge fund strategies or funds with different styles. Investors need to be familiar with the principles that enable them to understand hedge fund performance behaviour. Although many studies describe the role of factors or exposures of hedge funds in delivering excess returns to investors, there is no survey that summarizes and discusses the results. This issue creates confusion to investors who do not have a clear picture or a holistic interpretation of the dynamics of hedge fund performance attribution.

The present study therefore closes an important gap. The aim of this study is to survey the literature and investigate the hedge fund return generating process within implicit or statistical factor models. This is the first survey and synthesis of older literature to yield a historical perspective, along with a survey in more detail of recent innovative studies that depict advances in hedge fund performance attribution ${ }^{1}$. Hence readers will have an integrated view and a deeper understanding of hedge funds. Our findings both make life easier for hedge fund investors and highlight opportunities for further research.

Our main conclusions are that early studies (e.g. Sharpe, 1992), through the use of Principal Component Analysis and Common Factor Analysis (the most common statistical approach) dealt mainly with linear factor models, giving weight to the asset 
categories or where the fund manager invests. They depicted a static representation of hedge fund performance attribution. Then there was a development toward non-linear models that tried to explain hedge funds' performance as option portfolios (e.g. Fung and Hsieh, 2004; Agarwal and Naik, 2004). Nevertheless, in recent years there have been several studies (e.g. Patton and Ramadorai, 2013; Bali, Brown and Caglayan, 2014; O’Doherty, Savin, and Tiwari, 2015) that use more advanced models regarding hedge fund exposures. They confirmed previous studies that hedge funds have nonlinear returns in relation to the market return, but they moved further and showed how these non-linear exposures change over time according to financial conditions. Different strategies frequently have different exposures. However, there are a few exposures that are valid for virtually every hedge fund strategy (equity market, volatility, liquidity). Furthermore, systematic risk and more specifically macroeconomic risk have a significant role in explaining hedge fund performance for nearly all strategies. Higher moment factors provide extra explanatory power to the models.

This paper makes a number of important contributions to the understanding of the hedge fund literature. First, it covers a significant gap by presenting a survey that summarizes and discusses studies examining hedge fund performance attribution within statistical factors and exposures. It demonstrates a historical perspective by combining earlier and more recent innovative studies, discussing their strengths and weaknesses. Therefore the reader is able to look at the dynamic nature of the literature explaining hedge fund returns. This study assist investors in their asset allocation process in two ways: it facilitates a deeper understanding of what is behind hedge fund return variation and it also enables investors to know what to foresee from funds with different strategies or fund styles. Last but not least, we have identified some gaps for 
future research. An example is the absence of a unified framework that takes into consideration the comprehensive macroeconomic environment along with the internal structure of the hedge fund industry in explaining returns, or identifying the proportion of alpha affected by each of the underlying factors.

We start off in section 2 with a review of extant hedge fund literature review papers. In section 3 we depict different general approaches in measuring the performance of all hedge fund strategies ${ }^{2}$. Section 4 briefly reviews earlier linear studies. Section 5 reviews in detail the most recent non-linear models within the bottom-up, up-bottom, and alternative modeling approaches, as we describe later. In the final section 6 we summarize the key conclusions and reveal some gaps that should be addressed in future research.

\section{Extant Hedge Fund Literature Review Papers}

In this section we briefly discuss the extant hedge fund literature surveys. These consist of two very recent and two earlier papers. They deal with different aspects of hedge funds, including hedge fund performance attribution that we address specifically in this paper. For brevity we do not review the papers covered in these papers, as many of them are covered later in this paper and the reader can also refer to these other review papers.

An interesting general study is from Getmansky, Lee, and Lo (2015) that replicated many previous studies using Lipper TASS database from 1996 to 2014. It focused on several perspectives, offering a set of insights into the financial system with implications for the efficient market hypothesis, financial regulation and systematic 
risk among other areas. Getmansky et al. considered four perspectives on the hedge fund industry: the investor's perspective, the manager's perspective, the regulator's perspective and the academic perspective. By reviewing several aspects of the hedge fund literature and their implications for stakeholders in the hedge fund industry the authors shone a light on two investors' myths: first, that hedge funds comprise a homogenous asset class that have similar investment characteristics and returns, and second that all hedge funds are unique with no commonalities and, hence, no implications for diversification or systematic risk.

Similar to the above is a survey from Agarwal, Mullally, and Naik (2015) in that it examined several aspects of hedge funds such as hedge fund performance (time-series and cross-sectional variation), the sources and nature of risks related to managerial incentives and sources of capital, and the role of hedge funds in the financial system. Concerning performance evaluation and attribution, the authors suggested that the spectrum of risk factors explaining hedge funds variation is very broad. The key challenge is the identification of a parsimonious set of factors with greater availability of time-series data. This is because with more data we are more likely to be able to eliminate spurious factors that do not stand the test of time. Finally, the authors assert that there is substantial evidence that at least a subset of hedge fund managers possess skill. Specifically there is evidence of managerial skill in terms of their timing ability and their delayed disclosure of certain security holdings.

An earlier study came from Fung and Hsieh (2006). They examined the growth of the hedge fund industry as it evolved into adolescence using the TASS, HFR, and CISDM databases using the framework from their 1997 paper. By putting forward a simple model of how hedge funds do business they pulled together some of the important 
issues involving investors in hedge fund products, financial intermediaries, and regulators into a single framework. This framework revealed a fundamental question regarding the identification of systematic risk factors inherent in hedge fund strategies. In addition, the identification of these risk factors was the key input to important questions such as optimal contrast design between buyers and sellers of hedge fund products and explaining large changes in the hedge fund industry. In their simple hedge fund business model the authors argued that apparent style changes are consistent with fund managers maximizing their enterprise value, by diversifying the impact of different life cycles of hedge fund strategies. Moreover the pricing discovery process of a hedge fund firm favors those fund managers with a steady, diversified stream of fee income. Thus this could reduce excessive risk taking by individual fund managers.

Given that there is a concern over whether traditional metrics and tools for portfolio measurement and risk management are applicable to hedge funds (e.g. due to serial correlations in fund returns caused by illiquidity and smoothed returns), Lo (2005) briefly reviewed and described hedge fund properties. He also developed new tools and metrics when analyzing hedge funds. Using the CSFB/Tremont indices and the TASS database and applying an econometric model using smoothed returns and adjustments for the Sharpe ratio and other risk and return metrics, Lo showed that serial correlation can have a significant impact on performance measures such as the Sharpe ratio, with an overstatement of approximately 70 percent. He also addressed how liquidity can be integrated into the portfolio construction process so as to deliver optimal mean-variance-liquidity portfolios. Moreover Lo suggested that hedge funds' positive alphas come not only from seeking returns but also from adroit risk 
management. Understanding the risk preferences of investors and fund managers is an important element for proper risk management and investment policy.

In summary, four papers in the last decade conducted reviews of the academic literature on hedge funds. They reached several valuable conclusions, however no review paper has concentrated on how hedge fund returns have been explained. It is this that we focus on in the rest of this paper, looking in particular at recent work on non-linear models that had not been done at the time of the Lo (2005) and Fung and Hsieh (2006) papers. However, we start in section 3 by describing different general approaches towards hedge fund performance measurement.

\section{Model Categories}

In this section we present two general categories of models: absolute pricing models and relative value models. Then we focus on two different statistical approaches: Principal Component Analysis and Common Factor Analysis.

Generally speaking, asset pricing models are divided into two main categories: $(i)$ absolute pricing models and (ii) relative value models (Lhabitant, 2004 and 2007). The first category consists of fundamental equilibrium models and consumption-based models in combination with many macro-economic models. They use asset pricing theory and price each asset individually taking into consideration its exposures. They give an economic interpretation of why prices are what they are and why exposures are what they are. In addition they are supposed to predict price changes due to economic structure changes. The second category of asset pricing models explores the evidence of the different asset pricing rather than trying to fit an explanation of the financial 
markets. They price each asset by taking into consideration the prices of some other assets that are extraneous. In other words, they provide a plain illustration of how the financial world works. A typical well known example is the Black-Scholes (1973) formula that computes an option price in regard to its underlying asset price, disregarding whether that asset is fairly priced by the market. The factor models that we mention in this study belong to the category of relative price models. They price or evaluate hedge funds in regard to the market or any other risk factors. They do not concentrate on what induces the primitive factors, the market or factor risk premium, or the risk exposures accepted by the fund managers.

The majority of the factor (or relative price) models in this study use a two-stage approach: At the beginning, they hypothesize that hedge funds returns are specific functions of macro-economic and micro-economic factors (variables). Second, they test those initial assumptions and assess the sensitivity of hedge funds returns to those assumptions. Factor models determine the relationships between a large number of variables (for instance fund returns) and describe these relationships in terms of their common underlying dimensions, so called 'factors'. Hence, there is the advantage of dimensionality reduction because it sums up the information that is contained in a large number of original values (hedge funds returns) into a smaller set of factors with a minimum loss of information. In other words, via factor models we simplify the covariance matrix (correlation or covariance among the returns of all hedge finds).

Amenc, Sfeir and Martellini (2002) report four types of factor models. These are: (1) Explicit macro factors: These are macro-economic variables that are calculated either as predictive variables or adopted ex-post to measure market sensitivities in relation to some macroeconomic parameters. (2) Explicit index factor model: In these models 
each factor is investable and represents some index or fund available as an ETF (Exchange Trading Funds) or futures contract. (3) Explicit micro factor models: These microeconomic parameters (or variables) that refer to fund-specific features are estimated and forecast in a comparable manner as the explicit factor models. (4) Implicit factor models: These implicit factors are mainly derived through Principal Component Analysis (PCA) or Common Factor Analysis (CFA) and are regarded as a merely statistical approach. An analogous classification is suggested by Connor (1995) with the use of three types of factor models that are available for examining asset returns, named as: Macroeconomic factor models, Fundamental factor models and Statistical factor models.

In this part of our review we deal with statistical or implicit factor models. Regarding those factor models there are two widely-used methodologies that are used to distinguish the underlying factors: (i) Principal Component Analysis (PCA) and (ii) Common Factor Analysis (CFA). We explain and analyse those two methodologies and studies with regard to hedge funds.

\subsection{Principal Components Analysis}

The PCA methodology was first described by Pearson (1901). Implicit factors are obtained via this approach. The purpose is to explain the return series of observed variables via a smaller group of non-observed implicit variables. Those implicit factors are extracted from the time series of returns. In other words, the main objective of PCA is to explain the behaviour of a number of correlated variables using a smaller number of uncorrelated and unobserved implied variables or implicit factors called principal components. 
Fung and Hsieh (1997) used PCA to extract implicit factors in order to provide a quantitative classification of hedge funds based on returns alone. They took into consideration the location (market) as well the strategy (investment style) followed by managers. The returns are supposed to be correlated to each other even though they might not be linearly correlated to the returns of asset markets. They used a database (1991-1995) from Paradigm LDC and from TASS Management. They found that five principal components jointly accounted for $43 \%$ of the return variance of hedge funds. They assigned concise names to these components: (1) Trend-following strategies on diversified markets such as managed futures and CTAs (Commodity Trading Advisors), (2) Global/macro funds, (3) Long/short equity funds, (4) Funds with trendfollowing strategies specialized in major currencies, (5) Distressed securities funds.

Later, Amenc, Martellini and Faff (2003) used PCA in creating a passive hedge fund index or index of indices. Their method was a natural generalization of the equally weighted portfolio of indices. Using PCA they created a portfolio of indices with appropriate weights so that the combination of indices captured the largest possible amount of information contained in the data (time-series returns) of those indices. The first component was a candidate for a pure style index. This component caught a large percentage of cross-sectional variation due to the fact that those competing indices tend to be highly positively correlated. They proved mathematically that an index of indices is always more representative than any competing index upon which it is based. Furthermore, an index of indices is consistently less biased than the average of the set of indices it is derived from.

Additional authors who used PCA are Christiansen, Madsen and Christiansen (2003) so as to identify the minimum number of components needed to describe the returns 
of hedge funds from the CISDM database (1999-2002). They found that there were five components, and by comparing these with the qualitative self-reported classifications of hedge funds they identified five different strategies that could explain greater than $60 \%$ of hedge fund return variation (Opportunistic/Sector, Event Driven, Global Macro, Value and Market Neutral Arbitrage). It is evident from the above papers that using four to five components is sufficient to explain a large part of hedge fund returns.

\subsection{Common Factor Analysis}

The second statistical approach that is used more often in the literature is the Common Factor Analysis (CFA). Its goal is identical to PCA, which is to transform a number of correlated variables into a smaller number (dimensionality reduction) of uncorrelated variables, that is, factors. Nevertheless, there is a great difference with PCA. Here, the underlying factors are observable and clearly stated by the researcher carrying out explanatory and/or confirmatory analysis. They are not just implied by the data. As with PCA, the number of factors should be as small as feasible in order to have the advantages of dimensionality reduction. However, the researcher is making a trade-off between the dimensionality reduction and the accuracy she wants to maintain.

It is very common in factor analysis to choose factors on an ad hoc basis. The basic principle is to pick up variables that are considered most probably to influence asset returns. A researcher should take into consideration quantitative and qualitative approaches in order to decide which factors to use. Furthermore, a researcher should look for evidence from the empirical asset pricing literature. For many years 
researchers looked for factors ${ }^{3}$ that explained and influenced the cross-sections of expected returns.

Certain models that are extensions of the basic CAPM model have heavily influenced hedge funds models. These are Fama and French (1993), using the size and book to price ratio and Carhart (1997) that included the momentum as a fourth factor. Other more recent models are Fung and Hsieh's (2004) seven factor model, or Capocci's (2007) fourteen factor model. In the following two sections we present some earlier and some more recent studies using implicit factor models that are useful to reveal hedge funds exposures and explain their returns. A branch of the CFA approach is the Asset-Based style (ABS), factors where the factors are constructed by trading in the appropriate securities within the underlying conventional assets (e.g. bonds or equities) that mimic the returns of hedge funds (please see section 5.1).

Last but not least, one important application of factor models is hedge fund replication. There is a distinction between traded factors (e.g. market and size factors) and nontraded factors (e.g. volatility or liquidity), the latter of which are not readily tradeable. Investors may therefore encounter problems in their replication. In general, the same issues arise in the context of non-linear models where some of them do not allow for easy replication of hedge funds.

\section{Linear Factor Models}

In this section we briefly discuss some linear multi-factor models that are considered to be key studies in the hedge fund literature ${ }^{4}$. It is known that linear multi-factors models are based on the general linear equation model (Ross, 1976). In addition to the 
market factor (Sharpe, 1964) the most popular is the Fama and French (1993) model with the SMB (small minus large) and HML (high minus low book to market ratio) factors. Carhart (1997) was the first who used the momentum factor (Jegadeesh and Titman, 1993) as the fourth factor - a zero investment portfolio that is long in past winners and short in past losers. His model is an extension of the Fama and French factor model. All these previous factors are extensively used in the hedge fund academic literature.

We first consider style analysis-trading factors so as to introduce the reader gently to further linear and non-linear models. Therefore, we start from Sharpe (1992). Sharpe used an asset class factor model implementing style analysis as a substantial complement to other methodologies designed to assist investors achieve their targets in a cost-effective manner. He used a model composed of twelve asset classes to analyse the performance of funds between 1985 and 1989. The twelve asset classes were: (1) T-bills, (2) Intermediate-term Govt. Bonds, (3) Long-term Govt. Bonds, (4) Corporate Bonds, (5) Mortgage-Related Securities, (6) Large Cap Value Stocks, (7) Large Cap Growth Stocks, (8) Medium Cap Stocks, (9) Small Cap Stocks (10) NonU.S. Bonds, (11) European Stocks and (12) Japanese Stocks. The variation of fund returns in any specific period could be associated with the combined effects of their exposures to these asset classes and the realized returns on these classes. Those investors' exposures to asset classes were a function of, first, the proportion of the investor's portfolio invested in the various funds and second the exposures of each given fund to the asset classes. The exposures of a fund to wider asset classes depended on two elements: the amount of money that the fund had invested in various securities and the exposures of the securities to the asset class. 
Sharpe's (1992) style analysis can be used to appraise the behaviour of a fund manager's exposures to asset classes over a specific time period. Moreover it can be used to measure a fund manager's relative performance, in other words the value added by her skills (alpha). A passive hedge fund manager provides investors with an investment style whereas an active hedge fund manager provides both style and selection. Thus we can determine the terms of active and passive management. An investor may choose a set of asset classes that is superior to the performance of the 'standard' static mix and fulfils the requirement for higher fees. As a result, fund selection return according to Sharpe (1992) is denoted as the difference between the fund's return and that of a passive mix with the same style. Once the styles of an investor's funds have been estimated it is possible to estimate the effective asset mix. The effective asset mix reflects the style of the investor's overall portfolio.

The model for explaining the results of traditional mixed funds (composed of equities and bonds) first introduced by Sharpe (1992) is limited to funds that pursue a longonly strategy. However, hedge funds are much more flexible and can also use short selling and leveraging. These trading strategies of hedge funds lead to option-like structures that are not covered by the basic Sharpe model or other similar models. Confronting that problem, Fung and Hsieh's (1997) study is presented in section 5.1 dealing with non-linear factor models.

Schneeweis and Spurgin (1998) used factors designed to capture the trading opportunities available to CTAs or hedge funds as a means of forecasting return performance. They used the databases of HFR, EACM, MAR and Barclays from 1990 to 1995 . They considered the following factors to examine the returns to active management of hedge funds, CTAs and mutual funds: (1) a natural return to owning 
financial and real assets, (2) the use of both short and long positions, (3) the exploitation of the indices' intermonth volatility and (4) the exploitation of market inefficiencies that result in temporary trends in prices. These factors were able to significantly explain the differences in investment returns within each investment grouping. Using multivariate regressions they showed that CTA returns are positively related to commodity market trends. Hedge funds were related to the returns of the index which they were investing, whereas they offer higher returns than CTAs for any given level of risk.

A few years later, Capocci and Hubner (2004) examined hedge funds' behaviour from 1984 to 2000 (HFR, MAR) using various asset pricing models. Those included an extended form of Carhart's (1997) model, combined with the Fama and French (1998) and Agarwal and Naik (2000) models plus one more factor that takes into consideration the fact that hedge funds may invest in Emerging Markets. According to the authors, that combined model better explained variations of hedge funds over time than other studies, especially for Event Driven, U.S Opportunities, Global Macro, Equity non-hedge and Sector Funds. The performance analysis showed that one quarter of individual hedge funds delivered significant positive excess returns. The majority of them preferred to invest in smaller stocks and also invest in emerging markets bonds. Nine out of twelve strategies offered significantly positive returns. Most Event Driven, Market Neutral and US Opportunistic funds prefer stocks with high book-to-market ratios.

To sum up, there are several studies (e.g. Sharpe, 1992; Capocci and Hubner, 2004) that examined hedge fund performance under a linear framework. However, linear models are more suitable for traditional mixed funds (investing in equity and bonds). 
Moreover they cannot capture the time variation of funds' exposures. Some of these issues are addressed by the non-linear factor models that are presented in the following section $^{5}$.

\section{Non Linear Factor Models}

Beyond the linear factor models that were used for explaining hedge fund returns during the earlier years there is a development toward non-linear models. These try to capture the exposures and the non-linear payoffs of hedge fund returns in relation to their risk or market returns ${ }^{6}$. In general, there are two different approaches: bottom-up (or indirect) and up-bottom (or direct). The former starts with the underlying assets (e.g. stocks or bonds) to find the sources of hedge funds' returns. It involves replicating hedge fund portfolios by trading in the correspondent securities. These trading constructed factors are defined as asset-based style (ABS) factors (Fund and Hsieh, 2002a). The latter approach starts with identifying the sources of hedge fund returns and relates pre-specified risk factors for hedge fund performance attribution. It uses additional factors that better explain hedge fund returns. We also present a third approach (an extension of the up-bottom) that deals with methodological issues and tries to identify funds' structural breaks ${ }^{7}$.

\subsection{Bottom-Up Approach}

\section{Option Portfolios and Trend Followers}

In this sub-section, we begin with Fung and Hsieh (1997) who provided a useful characterization of the type of option strategy that one should expect when analysing hedge fund returns. Then we proceed with the Fung and Hsieh (2001) study which 
showed how to model hedge funds returns by concentrating on the 'trend-following' strategy. Examining futures and option futures, they demonstrated empirically that the returns of trend-following funds resemble lookback straddle returns ${ }^{8}$. Fung and Hsieh (2002a) extended their 2001 study to construct asset-based style factors. They demonstrated a model that could predict the returns behaviour of trend following strategies during certain market conditions. Fung and Hsieh (2004) was another extension of their previous work in 2001 and 2002a on asset-based style (ABS) factors. It proposed a model of hedge funds returns that is comparable to models depending on arbitrage pricing theory with dynamic risk coefficients. Huber and Kaiser (2004) confirmed Fung and Hsieh $(1997,2001)$ that CTAs have a payoff profile similar to a long straddle .

The authors Fung and Hsieh (1997) raised the issue of considering hedge funds as option portfolios. Their study is an extension of Sharpe's (1992) style analysis as beyond the "location" component or factor of returns (which tell us the asset categories or where the manager trades using a static buy and hold policy) they added two other components: 'Trading strategy factors' (the way the manager trades, denoting the type of dynamic strategy) and the 'leverage factor' (a scaling factor, the quantity that is invested and regarded as a component of the return). In order to quantify their statement (modelling hedge funds as option portfolios) and identify the location and trading strategy factors, the authors used a relatively simple method that is equivalent to non-parametric regression. They compared the performance returns of hedge funds strategies versus U.S. equities (S\&P 500) in five different economic conditions (from worst to best). As suspected the short-only strategy had no option-like feature and behaved almost exactly the opposite of equities. The CTA strategy had a return profile close to a straddle on equities. The global macro strategy performed like a short put 
on the S\&P 500 and had an approximately linear profile with regard to the USD/JPY exchange rate. Finally, the distressed securities and risk arbitrage strategies also behaved like short puts on the S\&P 500. Ultimately, Fung and Hsieh (1997) provided a convenient characterization of the type of option strategy that one should anticipate when dealing with funds' returns, as hedge fund strategies are highly dynamic (e.g. using derivatives, short-selling etc.). Moreover, their study showed that there are five dominant strategies ${ }^{10}$ in hedge funds having lower correlations with standard asset returns and mutual fund returns.

A few years later, Fung and Hsieh (2001) showed a way to model hedge funds returns by concentrating on the well-known 'trend-following' strategy. They examined futures and option futures from the Futures Industry Institute (FII), The Chicago Mercantile Exchange (CME) and Datastream. They used a general methodology for understanding hedge fund risk by modeling a specific trading strategy which is widely referred as "trend following" within the industry. They demonstrated empirically that the returns of trend-following funds resemble lookback straddle returns. They explored hedge funds returns through modelling the differences between trendfollowing and market-timing as trading strategies.

Given the market prices in any specific time period, the optimal pay-out of any trendfollowing strategy should be equal to the one that bought at the lowest price and sold at the highest price. It was for this reason that Fung and Hsieh (2001) suggested using a lookback straddle. Indeed, the lookback straddle is of specific interest due to its close connection to the return profiles of trend-following hedge funds. The majority of CTAs or managed futures funds are in fact 'trend-followers' (or primitive trading strategies). The payoff of a perfect market timer who may take long only positions 
should be very similar to the payoff from holding a call option. However, if the flawless market timer may take long or short positions, this would correspond to a perfect trend follower who could 'buy low and sell high'. This is equivalent to the payoff of a lookback straddle. Therefore, the lookback straddle can be regarded as a primitive trading strategy exploited by market timers.

Fung and Hsieh (2001) showed that a lookback straddle is better fitted to capture the principle of trend following strategies than simple standard asset benchmarks. Trendfollowing funds have a systematic risk that cannot be captured by linear-factor models applied to standard asset benchmarks. Also, trend-followers or portfolios of lookback straddles can reduce the volatility of a typical bond and stock portfolio during severe market downturns. However, it is important to mention that it is not possible to have a unique benchmark that can be used to model the performance of every trend follower. That is because there are significant dissimilarities in trading strategies among trend-following funds.

Extending their 2001 study, Fung and Hsieh (2002a) used previously-developed models to build asset-based style factors. They demonstrated a model that can predict the returns behavior of trend following strategies during certain periods and particularly during stressful market conditions such as those of September 2001. In this study the authors added almost four years of data (1998 to 2001) since their publication of 2001. Hence, they provided out-of-sample validation for their finding that trend followers have returns characteristics that mimic the payout of a lookback option on traditional assets. They showed that it is beneficial to model hedge funds strategies using asset-based style factors. Hedge fund directional strategies can be 
modelled with "long only" asset-based style factors and the "directional component" represents more than 50 percent of the hedge fund return variation.

Fung and Hsieh's 2004 study was an extension of their previous 2001 and 2002 papers on asset-based style (ABS) factors. It proposed a model of hedge fund returns that is comparable to models based on arbitrage pricing theory, with dynamic risk coefficients. They examined data from HFR and TASS databases for 1998 to 2002 and identified seven ABS factors to create hedge fund benchmarks that capture hedge funds' common risk factors. The seven ABS factors were two equity factors (market and size), two fixed income factors (change in bond yield and change in credit spread yield), and three trend-following factors (lookback straddles on bonds, commodities, and currencies). Using funds of funds as a proxy for hedge fund portfolios these factors were able to explain up to 80 percent (as represented by the R-squares and depending on which time period they used) of monthly return variations. Regarding the average hedge fund portfolio (using as proxy the HFR fund of funds index), they found that it had systematic exposures to directional equity and interest rates odds (bets), but they also had exposures to long equity and credit events. The authors also used the Kalman Filtering technique with a set of exogenous market events (e.g. LTCM, 09/11) for result verification ${ }^{11}$.

The final paper that we cover in this section on non-linear models is Huber and Kaiser (2004). They supported Fung and Hsieh $(1997,2001)$ in that, because hedge funds trade in a flexible way, their strategies lead to option-like structures that cannot be covered by the classic Sharpe model. They explained how these option-like structures come about. Thus hedge funds and CTAs using certain trading strategies generate returns similar to options. In particular, the structures of CTAs have a payoff profile 
similar to a long straddle. In their research, the authors presented an investigation of the risk factors affecting the nine Standard \& Poor's Hedge Fund Indices. Daily data about hedge funds indices were available from 1998 to 2003. The highest return was achieved by the Equity Long/Short basket (23.6\% p.a.) followed by Convertible Arbitrage (21.8\%) and Managed Futures (19.2\%). The poorest performers were Fixed Income Arbitrage (3.9\%) and Merger Arbitrage (6.9\%). The authors used the classical Sharpe model equation using several factors $F_{k}$. The empirical section of their study explained the risk factors of the Standard \& Poor's Hedge Fund Indices taking the option-like futures into account. For instance merger arbitrage had a significant determinant similar to a short put on the S\&P index, and managed futures, a long straddle on the S\&P 500 index.

\section{Option-Based Buy and Hold Strategies}

In this sub-section we present the other line of research originating from Agarwal and Naik (2000), who suggested a general asset factor model consisting of excess returns on passive option-based strategies and on buy-and-hold strategies. In a later study (2004) they focused on the systematic risk exposures of hedge funds that practise buyand-hold and option-based strategies. A more recent study that we discuss is from Duarte, Longstaff, and Yu (2007) that focuses on fixed income strategies, showing that "market neutral" strategies impose substantial risk exposures on investors.

Agarwal and Naik (2000) suggested a general asset factor model consisting of excess returns on passive option-based strategies and on buy-and-hold strategies. Despite the fact that many hedge funds implement dynamic strategies, they found that a small number of simple option writing/buying strategies were sufficient to explain a large 
part of the variation in hedge fund returns over time. Using the Hedge Fund Research Database from 1990 to 1998 (hedge fund indices), they evaluated the performance of hedge funds that adopted different strategies (especially Event Driven and Relative Value Arbitrage) using a general asset class factor model composed of excess return on Location (buy-and-hold) and on Trading Strategy (option writing/buying) factors.

Agarwal and Naik presented four main findings: First their model composed of Trading Strategy factors and Location factors was able to interpret a significant amount (up to 93\%) of hedge funds' returns over time. Second, non-directional strategies displayed more significant loadings on Trading Strategy factors whereas directional strategies displayed significant loadings on Location factors. They found that in the early 1990s $38 \%$ of hedge funds added significant value (excess return or alpha) compared to $28 \%$ of hedge funds that added value in the late 1990 s. Last but not least, leveraged funds did not consistently perform better or worse than funds that did not use leverage.

Likewise, in 2004 the same authors examined the systematic risk exposures of hedge funds practicing buy-and-hold and option-based strategies. They used data from HFR and TASS (hedge fund indices, 1990-2000). They found that a large number of equityoriented hedge funds strategies had payoffs similar to a short position in a put option on the market index. This was in alignment with findings from other studies such Awargal and Naik (2000) and Fund and Hsieh (1997) concerning the payoff style of some hedge funds strategies. They found that a short position in a put option on the market index brought a significant left-tail risk that was not captured sufficiently in the mean-variance framework. Hence, they used a mean-conditional value-at-risk framework and they demonstrated the degree to which the mean-variance framework 
underestimated the tail risk, also showing that the last decade is not representative of long term hedge fund performance.

In order to identify the linear and non-linear risks of a wide range of hedge funds strategies they used buy-and-hold and option-based risk factors. They followed a three-step approach: First they considered the loading coefficients (betas) using the returns of standard asset classes and options on them as factors. Then they constructed replicating portfolios that best explained the in-sample variation in hedge funds returns. Finally they examined how well those replicating portfolios caught the out-of sample performance of hedge funds. They conducted an analysis not only at the index level, but also at the individual hedge fund level. As well as their characterization of a non-linear relationship between portfolio return and its risk when examining hedge funds, Agarwal and Naik (2004) found that hedge funds exhibited significant exposures to Fama and French's (1993) three-factor model and Carhart's (1997) momentum factor.

A more recent study using the ABS approach was from Duarte, Longstaff, and $\mathrm{Yu}$ (2007) that examined the return and risk characteristic of fixed-income strategies using the CSFB/Tremont and HFR databases from 1994-2004. Implementing isotonic regression and linear-kernel regressions, they found all five strategies exhibited positive excess returns. Some strategies such as yield curve arbitrage, mortgage arbitrage and capital structure arbitrage presented significant positive alphas (even after taking fees into consideration) as they required the most "intellectual capital" to implement. They also found that, with the exception of the volatility arbitrage strategy, the returns had positive skewness. Moreover, several so called "market-neutral" arbitrage strategies imposed substantial risk exposures such as equity and bond market 
factors on investors. However, they found little evidence that these strategies exposed investors to substantial downside risk.

All the studies we have covered in this sub-section have been non-linear models that tried to explain hedge funds' performance as option portfolios. Fung and Hsieh (1997) provided a useful characterization of the type of option strategy that one should expect when analyzing hedge funds returns. Fung and Hsieh (2001, 2002) repeatedly demonstrated empirically that returns of trend-following strategies resemble lookback straddle returns. The same authors in 2004 presented the seven factor model that was able to capture the common risk ABS factors in hedge funds. Huber and Kaiser (2004) verified Fung and Hsieh (1997, 2001)'s results. They also showed that hedge funds (especially those using a convergence strategy) also have option-like return structures. Agarwal and Naik (2000 and 2004) suggested a factor model based on passive optionbased strategies and buy-and-hold strategies to benchmark the performance of hedge funds. Their findings were consistent with Fung and Hsieh (1997) concerning the payoff style of some hedge fund strategies. Duarte, Longstaff and Yu (2007) found that the so called market neutral strategies were not so neutral for investors and some fixed income strategies required the most "intellectual capital" to implement.

Although these studies are important to conceptually explain hedge funds returns using non-linear models, we believe that there is a weakness as those perspectives may not help investors in a practical way to choose and evaluate hedge funds. This is because, first, these exposures are not static and change very often (see sub-section 5.3) and, second, these factors are not easy to replicate by an investor. Moreover, some strategies (such as global macro or multi strategy) are not well defined hence are difficult to replicate. We discuss this issue further in section 5.3. 


\subsection{Up-Bottom Approach}

In this sub-section we deal with up-bottom approaches that in general use additional factors that better explain hedge fund returns and also statistical techniques refining these risk factors within the multi-factor models. Later studies, use more advanced econometric techniques. We begin with two studies of Patton (2009) and Bali, Brown, and Caglayan (2012) that have examined hedge funds' claim of market neutrality. Given the evidence that hedge funds contain systematic risk we proceed further to studies that attribute hedge fund performance to various risks.

\section{Market Neutrality}

An in-depth study of the dependence between hedge fund returns and the S\&P 500 index was carried out by Patton (2009) using the HFR and TASS databases from 1993 to 2003. He proposed five new neutrality concepts: mean neutrality, variance neutrality, value-at-risk neutrality, tail neutrality, and complete neutrality. The neutrality tests showed that about one quarter of funds in the market neutral category were significant non-neutral. For other fund styles the proportions of non-neutral funds are from $50 \%$ for fund of funds to $85 \%$ for equity non-hedge. Market neutral style funds were more neutral to market returns than other categories such as equity hedge, non-equity hedge, or event driven funds. Overall, even for market neutral funds there was significant and positive dependence between hedge fund returns and market returns.

A closely related study with the above came from Bali, Brown, Caglayan (2012) who examined how much the market risk, residual risk and tail risk justified the crosssectional dispersion in hedge fund returns, using the Lipper/TASS database from 1994 
to 2010. The authors separated the total risk into systematic and fund-specific or residual risk components. Using cross-sectional regressions, univariate and bivariate portfolio analysis they found that systematic risk was more powerful than residual risk in predicting the cross-sectional variation in hedge funds, even after taking into consideration various fund characteristics (e.g. fees, size and age). Furthermore, funds within the highest systematic risk quintile generated on average $6 \%$ higher annual returns than funds within the lowest systematic risk quintile. These results remained when using risk-adjusted returns as well. In addition the relationship between residual risk and future fund returns was insignificant.

\section{Dealing with Systematic Risk}

As we mentioned, given that hedge fund strategies are not as neutral as they claim (at least for the so-called market neutral strategies), there are studies that have examined the systematic risk that hedge funds impose on investors due to the market and the general macroeconomic environment that funds operate within. Ibbotson, Chen and Zhu (2011) examined hedge funds' alphas, betas and costs in a common framework. They used the TASS database and the sampling period was from 1995 to 2009. Fees were based on median fees - normally a 20 percent incentive fee and 1.5 percent management fee. Using regressions with the S\&P 500, U.S. intermediate-term government bond returns and U.S Treasury bills, they broke down average hedge funds annual returns of $11.3 \%$ into alpha (3.0\%), beta (4.7\%) and costs (fees, $3.43 \%$ ). Their results showed that alphas were positive even during the financial crisis in 2008 . The only exception was in 1998. Their results showed that a typical fund manager could add value in both bear and bull markets and their betas were in general reduced 
during bear markets. For example, during the technology bubble collapse fund managers underweighted equities in their portfolios.

A comparable study is from Bali, Brown and Caglayan (2011) who examined how hedge funds' exposures to various financial and macroeconomic factors could justify the cross-sectional variations in hedge fund returns. They used the Lipper/TASS database from 1994 to 2008 . Their most important finding was that there is a positive relation between hedge fund exposure to default risk premium and hedge fund future returns. This could be interpreted as a meaning that risk premia on risky assets are negatively correlated with present economic activity. For example, investors demand higher expected returns in recessions and lower expected returns in booms when holding risky assets. In a recession period, the default risk spread is high, so hedge funds with higher exposure to the default premium are expected to give higher returns. They also found that hedge funds with lower exposure to inflation derived higher returns in the future. This has to do with uncertainty. As inflation rises, there is uncertainty in the economy (as investors have changing expectations) and they expect to observe a decline not only in hedge fund values but also in other financial instruments. When inflation is stable and uncertainty is low then investors expect those hedge funds and other financial instruments to have attractive returns. Overall, nondirectional strategies (such as Fixed Income Arbitrage and Convertible Arbitrage) had lower variation and spreads in their exposures (beta factors) than directional strategies (such as Global Macro and Emerging Markets).

Extending their 2011 work, Bali, Brown, and Caglayan (2014) proposed custom measures of macroeconomic risk that could be regarded as measures of economic activity, using the Lipper TASS database from 1994 to 2012. The macroeconomic 
variables that the authors used were the default spread, term spread, short-term interest rates changes, aggregate dividend yield, equity market index, inflation rate, unemployment rate, and the growth rate of real gross domestic product per capital. By using cross sectional regressions and portfolio analysis, they showed that uncertainty betas can describe a significant proportion of cross section return differences between hedge funds (two exceptions were unemployment and short-term interest rate changes). More specifically, funds in the highest uncertainty index beta quintile delivered $0.80 \%$ to $0.90 \%$ higher monthly returns and alphas compared to funds in the lowest uncertainty index beta quintile. Moreover, the macroeconomic risk was a more powerful determinant on hedge fund returns than other commonly used financial risk factors (e.g. market returns, size, high minus low, momentum etc.). In addition, through the use of principal component analysis, the authors constructed an aggregate or broad index of macroeconomic risk whose first principal component explained about $62 \%$ of the corresponding hedge fund return variance. Moreover, directional strategies took direct exposure to the underlying macroeconomic risk factors and nondirectional strategies did not have significant macro-timing ability.

Analogous to that study but emphasizing forecasting more was the study by Avramov, Barras, and Kosowski (2013). They developed a unified methodological framework to asses both in-sample and out-of-sample hedge fund returns predictability based on macroeconomic variables, using the Barclayhedge, TASS, HFR, CISDM, and MSCI databases from 1994 to 2008. Beginning from in-sample analysis, approximately $63 \%$ of the sample funds had expected returns that changed according to business conditions. They used five macro variables (default spread, dividend yield, VIX index, net aggregate flows in the hedge fund industry) and found that returns predictability was widespread across different hedge fund strategies, consistent with economic 
intuition. A conditional (singe-predictor) strategy that forecast each macro variable (and selecting the top decile of funds with the highest return mean) was able to deliver superior performance. By diversifying across forecasts, the combination strategy is more sufficient when return forecasts are not sufficiently accurate, thus avoiding a poor fund selection.

Racicot and Theoret (2016), using strategy indices from the Greenwich Alternative Investment database from 1995 to 2012, examined the behaviour of the cross-sectional dispersions of hedge funds' returns, market betas and alphas during times of macroeconomic uncertainty. In their model they used the three Fama and French (1993) factors and the Fung and Hsieh (1997, 2001, 2004) lookback factors. Macroeconomic uncertainty was modelled using the conditional variances of six macro and financial variables (growth on industrial production, interest rate, inflation, market return, growth of consumer credit, and the term spread). Using the Kalman filter technique they found that hedge fund market beta reduces with macro uncertainty. This makes their strategies more homogeneous, resulting in a contribution to the increased systematic risk of the financial system. The dispersion of hedge funds returns and alphas increases during times of rising macroeconomic uncertainty.

Relevant to the above study is the study of Namvar, Phillips, Pukthuanthong, and Rau (2016) who used the CISDM and TASS Lipper databases from 1996 to 2010. Using Fung and Hsieh's (2004) factors in their model with PCA, time series and panel regressions, they examined the prevalence and the determinants of the systematic risk management (SRM) skill of fund managers and its effect on funds' performance over time. They used the spread between the AA and BB corporate bond index yields to define the strong, medium and weak market states. They found that during weak 
market states, skilled fund managers maintain low systematic risk via active adjustments to return factor loadings, even though that provides low excess return. In strong market states, skilled fund managers provide higher alpha than low skill managers through their superior asset selection ability. More experienced or more educated fund managers present higher SRM skill. Moreover, SRM is lower for managers who manage funds with distress indicators (e.g. low investor flows or poor performance).

\section{Higher Moment Risk and Refined Factors}

In this sub-section we present some studies that try to explain hedge fund performance attribution based on higher moment risk. For example, Agarwal, Arisoy and Naik (2016), using the Eurekahedge, HFR, Lipper TASS and Morningstar databases, from 2006 to 2012, investigated whether uncertainty about volatility of the market portfolio could explain the performance of hedge funds, both in the cross-section and over time. They measured uncertainty about volatility of the market portfolio with the volatility of the aggregate volatility (VOV) of equity market returns. They constructed an investable version of this measure by calculating monthly returns on lookback straddles on the VIX index. They found that there was negative relationship between VOV exposures and hedge fund risk adjusted returns; however, this was not homogenous across all hedge fund strategies. They also found that the VOX negative exposure was a significant determinant of hedge funds returns at the general index level, at different strategy levels, and at the individual level as well. Strategies with less negative VOV betas outperformed strategies with more negative VOV betas during banking crisis period. Conversely, strategies with more negative VOV betas 
delivered superior returns when the uncertainty in the market was less. Also funds' VOV betas had a significant ability to predict excess returns one month ahead.

Related to the above study was that from Hubner, Lambert and Papageorgiou (2015), who modelled hedge fund returns on a conditional asset pricing model using the information content of market skewness and kurtosis. They used the HFR database from 1996 to 2009 . They described the dynamics of the equity hedge, event-driven, relative value, and fund of funds styles and in their model considered the location, trading and the higher-moment factors. Within this framework they investigated the effect of the implied moments retrieved from the US equity markets and more specifically from the option-implied higher moments. The implied skewness and kurtosis of index portfolios increased the model's explanatory power and reduced the specification error for the majority of strategies. Market Neutral, Relative Value and Fund of Funds change their market exposure during financial crises. The authors recognized that an extension of their framework to other market types and locations would provide extra explanatory power to their model.

There are studies that use high frequency econometrics or refined statistical methods to choose the appropriate factors. For instance, Patton and Ramadorai (2013) proposed a new performance evaluation method that was based on Ferson and Schadt's (1996) model (a customized conditional model for mutual funds incorporating lagged information variables). That model was able to capture higher-frequency variations in hedge funds' exposures. They used the HFR, CISDM, TASS, Morningstar and Barclays databases and the sample period was from 1994 to 2009. In their factor model that included a simulation process, they used daily hedge fund (index) returns in relation to monthly hedge fund (individual) returns. They observed similar parameter 
estimates across the two sampling frequencies. Furthermore, hedge funds exposures varied across and within months. Moreover, they discovered patterns where the exposure variation was higher early in the month (immediately after the reporting date) and then got progressively lower until the reporting date. In addition, they found changes in portfolio allocations (weights) (that ultimately led to exposure changing) rather than changes in exposures to different asset classes and also a tendency to cut positions in response to significant market events (such as sharp changes in market returns or volatility). The authors' results showed that hedge funds, contrary to mutual funds, responded very quickly, were very flexible and adapted to any market triggers.

Brown (2012) proposed a specific framework for hedge fund return and risk attribution. He used the HFN and HFR databases and the sample period was from 1997 to 2010. In order to better estimate hedge funds fees, betas and alphas he suggested a framework that monthly returns be drawn from the following influences: fees (management and incentive fees) and four simple systematic risk factors. Those were volatility, leverage and two other more traditional factors such as equities, credit, interest rates, or commodities. For most fund strategies, volatility is the most important source of systematic risk. Brown applied stepwise regressions to various style or aggregate indices because of the need to customize performance benchmarks to different styles. He found that many hedge fund styles carried significant exposures to traditional systematic risk factors such as equities, interest rates or credit. Due to the fact that incentive fees are computed on total returns, there is a potential that abnormal returns attributed to those systematic exposures may overwhelm hedge fund alpha. Thus, fund managers may get paid for simple passive market exposures. Those problems of charging incentive fees on simple market exposures extend to most hedge fund styles and therefore constitute a barrier to their efficient usage. 
Lastly, Slavutskaya (2013) improved the out-of-sample accuracy of linear factor models by combining cross-sectional and time-series information (panel data methods) for groups of hedge funds with similar investment strategies. She used the TASS, HFR, CISDM, and Alvest databases from 1994-2009. She suggested that current factor models are over-parameterized which results in unstable estimates. The "shrinkage" estimate, which is the trade-off between the individual estimates and the common mean estimate (the average risk exposure of a particular hedge fund style) provided a more accurate estimate. More specifically, she found that the root mean squared monthly error in panel data models was $10-15 \%$ smaller than in linear regressions, and the rate of decrease is significant. Nevertheless, she pointed out that the use of cross-sectional beta estimates assumed that all funds had the same risk exposures for a given time.

\section{Holdings/SEC filings}

A study that focused on the funds' security holdings and stock-picking was that of Chung, Fung, and Patel (2015). They examined whether hedge funds deliver consistent superior performance by focusing long-equity holdings. They used four databases: GOEF, CRSP, data from French's website, and that of Orissa Group from 1997 to 2006. By focusing on the characteristics of returns associated with long-equity picks of hedge funds and other institutional investors, they showed that hedge funds presented stock-picking superiority on their loading on the market risk factor compared to other institutional investors across three different market eras: bubble, deflation, and recovery. Moreover, high information acquisition (high churn rate) and active portfolio management (high active share) appeared to be necessities for the superior returns of hedge funds relative to other institutional investors. 
Related to the above study is the paper by Agarwal, Jiang, Tang and Yang (2013) who examined the "confidential holdings" from hedge funds which are amendments to Form 13F (SEC's requirement of quarterly holdings report for funds with over $\$ 100$ million in qualifying assets), using the SEC's EDGAR database (1999-2007). The authors incorporated and compared confidential holdings' performance to original holdings' performance of fund managers' portfolios providing a clear picture of the stock-picking ability of hedge funds. They showed that confidential treatment provides an incentive for active portfolio managers and also relieves fund managers from having to reveal their private information before reaping the full benefits of their investments. Funds managing large risky portfolios with nonconventional strategies (e.g. higher idiosyncratic risk) pursue confidentiality frequently and confidential holdings exhibit superior performance from 2 to 12 months. Although the conventional $13 \mathrm{~F}$ databases which ignore confidential holdings may be biased, this bias is small when considering aggregate institutional holdings in public companies. However this is a significant omission when analyzing position changes of individual institutions or in response to certain events.

The above studies using additional factors and statistical techniques examined in detail systematic risk and performance, and the way they change according to financial conditions or holdings. However, more work is needed look at the time variation of hedge fund performance attribution. This is an issue that can better be captured with the identification of the structural breaks within the underlying models, as presented in section 5.3 . 


\subsection{Alternative Approach}

In this section we present studies that have addressed different methodological issues and tried to identify structural breaks in hedge fund returns. These studies focus on the model uncertainty and its different behaviour when describing hedge fund returns. As with the up-bottom approach, these studies also tend to use more advanced econometric techniques.

We begin with Bollen and Whaley (2009) who used the CISDM database from 1994 to 2005. They ran an optimal change-point regression model that allowed risk exposures to change-switch (although they implemented it using just one changepoint) and a stochastic beta model that used an autoregressive process for risk exposures. In order to select the most appropriate subset of available factors they first selected a subset of factors that maximized the explanatory power of a constant parametric regression by using the Bayesian Information Criterion. The change-point regression model performed better overall compared to the stochastic beta model, showing that approximately $40 \%$ of the hedge funds in their sample presented a significant shift in risk exposures. Moreover, for live funds, switches tend to take place early in the fund's life, whereas switcher funds tend to outperform non-switchers funds. Overall, time-varying risk exposures presented better estimates of funds' alphas and could make better hedge fund returns predictions.

Giannikis and Vrontos (2011) used the HFR database from 1990 to 2009 to examine the non-linear risk exposures of hedge funds to various risk factors. Their analysis revealed that different strategies exhibited non-linear relationships to different risk factors and that a threshold regression model incorporating a Bayesian approach 
improved the ability to appraise hedge fund performance. They used the Bayesian approach to identify the relevant risk factors (instead of stepwise regression or performing other statistical criteria) and at the same time detect possible thresholds in the model. The Bayesian methodology solved two problems of the regression models: first, the uncertainty of the set of the risk factors and, second, the number and the values of the appropriate thresholds. This was a probabilistic approach incorporating prior information - inferences appropriate to the underlying datasets. Finally, different hedge fund strategies presented different timing abilities.

One more recent innovative study was from Jawadi and Khanniche (2012). They used the CSFB/Tremont database (hedge fund indices) over the period 1994 to 2009. They examined the adjustment dynamics of hedge fund returns and their exposures in a nonlinear framework, and more specifically the smooth transition regression method. They found that the dynamics of hedge funds returns realized significant asymmetry and non-linearity in relation to the market return, showing that they changed and differed asymmetrically with respect to different financial conditions. Furthermore, hedge funds exposures varied over time depending on the strategy and regime. They advocated the superiority of non-linear models to capture the evolution of hedge funds exposures, especially during periods of financial crisis.

In the same year, Billio, Getmansky and Pelizzon (2012) examined hedge funds exposures using regime-switching beta models on data from the Credit Suisse/Tremont database from 1994-2009 (hedge fund indices). They noticed that hedge funds had non-linear exposures not only to the equity market risk factor, but also to the liquidity risk factor, volatility, credit, term spreads and commodities. Also, hedge funds changed their exposures when dealing with up, down, or tranquil regimes. 
Furthermore, they found that the S\&P 500, Credit Spread, Small-Large and VIX (measure of volatility in S\&P 500 index options - Chicago Board Options Exchange) were common hedge fund factors, especially in a falling market. The estimated exposures were unaffected even when authors de-smoothed the returns.

A related to the above study was from Akay, Senyuz and Yoldas (2013) who examined hedge fund industry contagion and time variation in risk adjusted return (alpha), using the Dow Jones Credit Suisse Hedge Fund Indices database from 1994 to 2010. They used a Markov regime switching model and found three regimes that could capture hedge fund returns dynamics: the first was the crash state with large negative mean and extreme volatility, the second regime was a low mean and high volatility state, and the third regime was a high mean state with minimal volatility. They also found evidence for a decline in risk adjusted returns for most investment strategies especially after the stock market crash in 2000. Moreover, they found that co-movement in hedge funds returns, after counting for common risk factors, was not only restricted to times of extreme financial turbulence. Last but not least, they linked the probability of observing the crash state to liquidity proxies and panic, measured by the VIX index and found that both played a significant role in leading to contagion.

A final study is from O'Doherty, Savin, and Tiwari (2015), using the Lipper TASS database from 1994 to 2011, implementing a pooled benchmark model by combining (with different weights) five linear models: five equity factors, three fixed income and commodity factors, three global factors, the five Fung and Hsieh (2001) trend following factors, and the four Agarwal and Naik (2004) option-based factors. Their optimal pool was based on the score log which was a measure of the conditional performance of a factor model, regarding its ability to track the monthly return for a 
given hedge fund. The authors verified that the above factors of the models capture hedge funds' exposures; in addition, their optimal pooled benchmark mitigated the (benchmark) error of these factor-based attribution models. Also the model pooling approach had more predictive power for failures among the funds in their sample than other performance attribution models.

To sum up, several studies that follow the bottom-up approach have examined hedge fund performance as a non-linear payoff of hedge fund returns in relation to market returns. However this method is not easily understood or implemented by investors. Moreover, there are some hedge fund strategies (such as multi-strategy and global macro) that are less well-defined, thus making replicating their returns through security trading a challenge. On the contrary, studies that follow the up-bottom and especially the alternative approach have the strength of showing greater flexibility in explaining hedge fund performance attribution. They support previous studies that hedge funds have non-linear returns and exposures and they show how these nonlinear exposures change over time. Different strategies usually have different exposures, although there are a few exposures that are valid for nearly every hedge fund strategy (e.g. equity market and volatility).

\section{Conclusion}

We have demonstrated how hedge funds returns can be explained using implicit or statistical factor models. We have presented a combination of older literature to give a historical perspective and recent papers to reveal advances in those topics. This review is important because is the first that presents and analyses very recent studies 
that explain a large part of the hedge fund return generating process, showing and discussing how the research has evolved.

Principal Component Analysis and Common Factor Analysis are the two widely-used statistical approaches that are used to distinguish the factors underlying hedge fund returns and we have presented these in detail. Concerning CFA, which is more common in the literature, early studies dealt mostly with linear factor models. Then there was a movement toward non-linear models that tried to explain hedge funds' performance as option portfolios. Non-linear studies may follow a bottom-up, an upbottom, or alternative approach (that is an extension of the up-bottom approach). Recently, there have been several studies using more advanced models regarding hedge fund exposures. They confirmed previous studies that hedge funds have nonlinear returns in terms of market returns, and they studied how their non-linear exposures change over time according to financial conditions. Different strategies usually have different exposures. However there are a few exposures that are valid for nearly every hedge fund strategy (e.g. equity market, volatility, liquidity). Macroeconomic risk has a significant role in explaining hedge fund performance for nearly all strategies. Moreover, higher moment factors can provide extra explanatory power to the models, and hedge fund managers in general show superior stock-picking ability compared to other institutional investors.

In this review we have presented and analyzed studies that try to explain hedge funds returns using implicit statistical factors. It is crucial for an investor or researcher to understand how hedge fund exposures change over time, taking into consideration their styles as well as the economic environment in which they operate. That environment is very dynamic, thus the researcher should incorporate those external 
variables into her model for more robust and reliable results. It is also helpful to understand the evolution and advances in hedge fund implicit factors so as to better evaluate hedge funds, or at least know what to expect from different hedge fund strategies or fund styles.

A limitation of our study is that we do not consider other aspects of hedge funds, for instance specific characteristics (e.g. fundamental factors such as size and lockup periods) that affect fund performance, fund performance persistence or qualitative performance criteria (e.g. fund investment policies or management experience). This is because our study specializes in the return generating mechanism of hedge funds within implicit or statistical factor models. Another limitation is that there are differences in studies due to industry heterogeneity and authors use different sample periods, datasets, and methodologies. However, this is a common issue faced by other authors. Even with this limitation, we have highlighted some consistent trends and conclusions that should be helpful to investors.

Possible directions for future research include, first, the external macroeconomic environment that hedge funds operate and, second, the internal structure of the hedge fund industry. Concerning the former, there is a need for a general comprehensive framework that includes the impact of economic policies (monetary and fiscal) on hedge funds' performance, or examining the impact of different market conditions in a holistic approach not isolating one or two only stressful economic events. However, this depends on hedge fund data availability for the earlier years. Concerning the latter, there is a need to examine the return generating mechanism within the hedge fund market microstructure. For example, the way that the working processes in the hedge fund industry relate to transaction costs, quotes, volumes, prices and trading behavior 
needs to be considered. Those elements have an impact on hedge fund exposures and returns.

\section{References}

Akay, O., Senyuz, Z., and Yoldas, E. (2013). Hedge fund contagion and riskadjusted returns: A Markov-switching dynamic factor model, Journal of Empirical Finance, 22(1), pp.16-29.

Agarwal, V., Arisoy, E., and Naik, N. (2016). Volatility of aggregate volatility and hedge fund returns, [Online]. Available at http://papers.ssrn.com/sol3/papers.cfm?abstract_id=2502352 [Accessed 01 June 2016].

Agarwal, V., Jiang, W., Tang, Y. and Yang, B. (2013). Uncovering Hedge Fund Skill from the Portfolio Holdings They Hide, The Journal of Finance, 68(2), pp.739780.

Agarwal V., Mullally, K., and Naik, N. (2015). Hedge funds: A survey of the academic literature, Foundations and Trends in Finance, Publishers Inc. pp.1-63.

Agarwal, V. and Naik, N. (2000). Performance evaluation of hedge funds with option-based and buy-and-hold strategies, [Online]. Available at http://papers.ssrn.com/sol3/papers.cfm?abstract_id=238708 [Accessed 15 October 2014].

Agarwal, V. and Naik, N. (2004). Risks and portfolio decisions involving hedge funds. The Review of Financial Studies, 17(1), pp.63-98.

Amenc, N. and Martellini, L. and Faff, R. (2003). Desperately seeking pure style indices, EDHEC-MISYS Risk and Asset Management Research Centre, [Online]. Available at http://citeseerx.ist.psu.edu/viewdoc/download?doi=10.1.1.114.4819\&rep=rep1\&type $=$ pdf [Accessed 28 October 2014]. 
Amenc, N., Sfeir, D. and Martellini, L. (2002). An Integrated framework for style analysis and performance measurement, [Online]. Available at http://www.edhecrisk.com/edhec_publications/RISKReview1048588983078116286/attachments/edhe c_perf_analysis.pdf [Accessed 01 October 2014].

Amihud, Y. (2002). Illiquidity and stock returns: cross-section and time series effects, Journal of Financial Markets, 5(1), pp.31-56.

Avramov, D., Barras, L., and Kosowski, R. (2013). Hedge fund return predictability under the magnifying glass, Journal of Financial and Quantitative Analysis, 48(4), pp.1057-1083.

Bali, T., Brown, S. and Caglayan, M. (2011). Do hedge funds' exposures to risk factors predict their future returns?, Journal of Financial Economics, 101(1), pp.3668.

Bali, T., Brown, S., and Caglayan, M. (2012). Systematic risk and the cross section of hedge fund returns, Journal of Financial Economics, 106(1), pp.114-131.

Bali, T., Brown, S., and Caglayan, M. (2014). Macroeconomic risk and hedge fund returns, Journal of Financial Economics, 114(1), pp.1-19.

Banz, R.W. (1981). The relationship between return and market value of common stocks, Journal of Financial Economics, 9(1), pp.3-18.

Basu, S. (1983). The relationship between earnings yield, market value and the return for NYSE common stocks: further evidence, Journal of Financial Economics, 12(1), pp.129-156.

Bhandari, L.X. (1988). Debt equity ratio and expected common stock returns: empirical evidence, Journal of Finance, 48(2), pp.507-528.

Billio, M., Getmansky, M. and Pelizzon, L. (2012). Dynamic risk exposures in hedge funds, Computational Statistics and Data Analysis, 56(11), pp.3517-3532. 
Black, F. and Scholes, M. (1973). The pricing options and corporate liabilities, The Journal of Political Economy, 17(1), pp.637-654.

Bollen, N. and Whaley, R. (2009). Hedge fund risk dynamics: Implications for performance appraisal, The Journal of Finance, 66(2), pp.985-1035.

Brown, R. (2012). Framework for hedge fund return and risk attribution, The Journal of Investing, 21(4), pp.8-23.

Capocci, D. and Hubner, G. (2004). Analysis of hedge fund performance, Journal of Empirical Finance, 11(1), pp.55-89.

Capocci, D. (2007). An analysis of hedge fund strategies, PhD Thesis Dissertation, [Online]. Available at http://www.opalesque.com/files/Thesis.pdf [Accessed 30 October 2014].

Carhart, M. (1997). On persistence in mutual fund performance, Journal of Finance, 52(1), pp.57-82.

Christiansen, C., Madsen, P. and Christiansen, M. (2003). A quantitative analysis of hedge fund style and performance, [Online]. Available at http://pure.au.dk//portal/files/12742/D03_5 [Accessed 30 October 2014].

Chung, R., Fung, S., and Patel, J. (2015). Alpha-beta-churn of equity picks by institutional investors and the robust superiority of hedge funds, Review of Quantitative Finance and Accounting, 45(1), pp.363-405.

Connor, G. (1995). The three types of factor models: A comparison of their explanatory power, Financial Analysts Journal, 51(3), pp.42-46.

Duarte, J, Longstaff, F., and Yu, F. (2007). Risk and return in fixed-income arbitrage: Nickels in front of steamroller?, Review of Financial Studies, 20(1), pp.770-811. 
Fama, E. and French, K. (1993). Common risk factors in the returns of stocks and bonds, Journal of Financial Economics, 33(1), pp.3-56.

Fama, E. and French, K. (1998). Value versus growth: The international evidence, The Journal of Finance, 13(6), pp.1975-1999.

Ferson, W. and Schadt, R. (1996). Measuring fund strategy and performance in changing economic conditions, Journal of Finance, 51(2), pp. 425-461.

Fung, W. and Hsieh, D. (1997), Empirical characteristics of dynamic trading strategies: The case of hedge funds, The Review of Financial Studies, 10(2), 275302.

Fung, W. and Hsieh, D. (2001). The risk in hedge fund strategies: Theory and evidence from trend followers, The Review of Financial Studies, 14(2), pp. 313-341.

Fung, W. and Hsieh, D. (2002a). Asset-based style factors for hedge funds, Financial Analysts Journal, 58(5), pp.16-27.

Fung, W. and Hsieh, D. (2002b). Risk in fixed income hedge fund styles, Journal of Financial Intermediate, 12(1), pp.6-27.

Fung, W. and Hsieh, D. (2002c). Extracting portable alphas from equity long-short hedge funds, Journal of Investment Management, 2(1), pp.57-75.

Fung, W. and Hsieh, D. (2004). Hedge fund benchmarks: A risk-based approach, Financial Analysts Journal, 60(5), pp.65-80.

Fung, W., Hsieh, D. (2006). Hedge funds: An industry in its adolescence, [Online], Available at https://www.frbatlanta.org/research/publications/economicreview/2006/q4/vo191no4_hedge-funds-an-industry-in-its-adolescence.aspx [Accessed 19 July 2016]. 
Getmansky, M., Lee, P., and Lo, A. (2015). Hedge Funds: A dynamic industry in transition, [Online], Available at http://alo.mit.edu/wpcontent/uploads/2015/08/HFReview_11b.pdf [Accessed 20 July 2016]

Giannikis, D. and Vrontos, I. (2011). A Bayesian approach to detecting non-linear risk exposures in hedge fund strategies, Journal of Banking and Finance, 35(6), pp.1399-1414.

Huber, C. and Kaiser, H. (2004). Hedge fund risk factors with option-like structures: Examples and explanations, The Journal of Wealth Management, 7(3), pp.49-60.

Hubner, G., Lambert, M., and Papageorgiou, N. (2015). Higher-moment risk exposures in hedge funds, European Financial Management, 21(2), pp.236-264.

Ibbotson, R., Chen, P.,CFA and Zhu, K. (2011). The ABC of hedge funds: Alphas, betas and costs, Financial Analysts Journal, 67(1), pp.15-25.

Jawadi, F. and Khanniche, S. (2012). Modeling hedge fund exposure to risk factors, Economic Modeling, 29(4), pp.1003-1018.

Jegadeesh, N. and Titman, S. (1993). Returns to buying winners and selling losers: Implications for stock market efficiency, Journal of Finance, 48(1), pp.65-91.

Lhabitant, Francois-Serge. (2004). Hedge funds: Quantitative insights, book, John Wiley \& Sons, Ltd, pp.87-98.

Lhabitant, Francois-Serge. (2007). Handbook of hedge funds, book, John Wiley \& Sons, Ltd, pp.487-490.

Lo, A. (2005). The dynamics of the hedge fund industry, Research foundation of CFA institute monograph, 35(4), pp.87-90.

Mitchell, M. and Pulvino, T. (2001). Characteristics of risk and return in risk arbitrage, Journal of Finance, 56(6), pp.2135-2175. 
Namvar, E., Phillips, B., Pukthuanthong, K., and Rau, R. (2016). Do hedge funds dynamically manage systematic risk?, Journal of Banking and Finance, 64(1), pp.115.

O’Doherty, M., Savin, N.E., and Tiwari, A. (2015). Evaluating hedge funds with pooled benchmarks, Management Science, (Articles in Advance), pp.1-21.

Patton, A. (2009). Are "market neutral" hedge funds really market neutral?, Review of Financial Studies, 22(1), pp.2495-2530.

Patton, A. and Ramadorai, T. (2013). On the high-frequency dynamics of hedge fund risk exposures, The Journal of Finance, 68(2), pp.597-635.

Pearson, K. (1901). On lines and planes of closest fit to systems of points in space [On line]. Available at http://stat.smmu.edu.cn/history/pearson1901.pdf [Accessed 26 September 2014].

Racicot, F.E. and Theoret, R. (2016). Macroeconomic shocks, forward-looking dynamics, and the behaviour of hedge funds, Journal of Banking and Finance, 62(1), pp.41-61.

Reinganum, M.R. (1981). Misspecification of capital asset pricing: empirical anomalies based on earnings yield and market values, Journal of Financial Economics, 9(1), pp.19-46.

Ross, S. (1976). The arbitrage theory of capital asset pricing, Journal of Economic Perspective, 13(3), pp.341-360.

Schneeweis, T. and Spurgin R. (1998). Multifactor analysis of hedge fund, managed futures and mutual fund return and risk characteristics, The Journal of Alternative Investments, 1(2), pp.1-24.

Sharpe, W. (1964). Capital asset prices: A theory of market equilibrium under conditions of risk, Journal of Finance, 19(3), pp.425-442. 
Sharpe, W. (1992). Asset allocation: Management style and performance measurement, The Journal of Portfolio Management, 18(2), pp.7-19.

Slavutskaya, A. (2013). Short-term hedge fund performance, Journal of Banking and Finance, 37(11), pp.4404-4431.

Stafylas, D., Anderson, K., and Uddin, M. (2016). Recent Advances in Hedge Fund Performance Attribution: Performance Persistence and Fundamental Factors, International Review of Financial Analysis, 43(1), pp.48-61 


\section{Appendix}

\section{Table 1. Performance Attribution - Linear Studies}

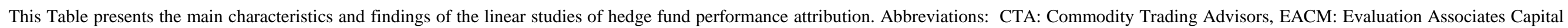
Market, HFR: Hedge Fund Research, MAR: Managed Account Reports. Some databases (e.g. Lipper and TASS, MAR and CISDM) have been merged.

\begin{tabular}{|c|c|c|c|}
\hline Study & Sample & Methodology & Findings \\
\hline Capocci and Hubner (2004) & HFR, MAR, 1988-1995 & $\begin{array}{l}\text { Regression based and } \\
\text { portfolio construction }\end{array}$ & $\begin{array}{l}\text { One quarter of individual hedge funds deliver significant positive excess returns. The majority of them } \\
\text { invest in smaller stocks and emerging market bonds having also exposure to the US bond market. Nine } \\
\text { out of twelve strategies deliver significant positive returns. Most Event Driven, Market Neutral, and US } \\
\text { Opportunistic funds prefer stocks with high book-to-market ratios }\end{array}$ \\
\hline Schneeweis and Spurgin (1998) & $\begin{array}{l}\text { HFR, EACM, MAR, Barclays, } \\
\text { 1990-1995 }\end{array}$ & Regression based & $\begin{array}{l}\text { CTA returns are positively related to commodities and currency movements whereas hedge fund } \\
\text { returns are related to the index returns invested. Hedge funds systematically offer higher returns than } \\
\text { either mutual funds or CTAs for any given level of risk }\end{array}$ \\
\hline Sharpe (1992) & $\begin{array}{l}\text { C. Jarrett \& Company, Inc., } \\
\text { 1985-1989 }\end{array}$ & $\begin{array}{l}\text { Regression based, } \\
\text { portfolio construction }\end{array}$ & $\begin{array}{l}\text { Focus on traditional mixed funds (composed of equities and bonds). Fund returns depend on their } \\
\text { exposures to the investable assets and their realized returns. Exposures to assets classes are a function } \\
\text { of the proportion of the investor's portfolio invested in various funds and exposures of each given fund } \\
\text { to the asset classes }\end{array}$ \\
\hline
\end{tabular}


Table 2. Performance Attribution - Non-linear Studies

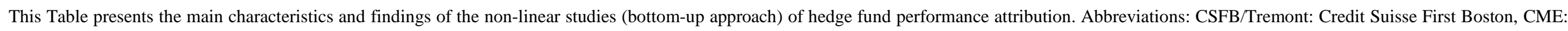

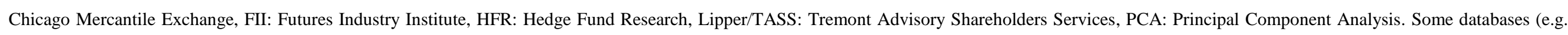
Lipper and TASS, MAR and CISDM) have been merged.

\begin{tabular}{|c|c|c|c|}
\hline Study & Sample & Approach/Methodology & Findings \\
\hline Agarwal and Naik (2000) & HFR, 1990-1998 & $\begin{array}{l}\text { Bottom-Up/Regression based, } \\
\text { portfolio construction }\end{array}$ & $\begin{array}{l}\text { Trading strategy and location factors are able to interpret a significant amount (up to } 90 \% \text { ) of hedge } \\
\text { fund returns. Non-directional strategies present more significant loadings on trading strategy factors. } \\
\text { Directional strategies present significant loadings on location factors. Only } 35 \% \text { of the hedge funds } \\
\text { have added significant excess returns to investors. Funds that use leverage do not necessarily } \\
\text { perform better or worse than funds that do not use leverage }\end{array}$ \\
\hline Agarwal and Naik (2004) & HFR, TASS, 1990-2000 & $\begin{array}{l}\text { Bottom-Up/Regression based, } \\
\text { portfolio construction }\end{array}$ & $\begin{array}{l}\text { Hedge fund strategies can have payoffs similar to a short position in a put option on the market } \\
\text { index and exhibit significant exposures to the size, value, and momentum factors. A short position } \\
\text { in a put option on the market index delivers a significant left-tailed risk that is not captured } \\
\text { sufficiently in the mean variance framework. The expected tail losses of mean-variance optimal } \\
\text { portfolios can be underestimated and the performance during the last decade is not representative of } \\
\text { hedge fund long-term performance }\end{array}$ \\
\hline $\begin{array}{l}\text { Duarte, Longstaff, and Yu } \\
\text { (2007) }\end{array}$ & $\begin{array}{l}\text { CSFB/Tremont, HFR, 1994- } \\
2004\end{array}$ & $\begin{array}{l}\text { Bottom-Up/Isotonic regression, } \\
\text { Linear-Kernel regression }\end{array}$ & $\begin{array}{l}\text { In general, fixed income arbitrage strategies deliver positive excess returns which are positively } \\
\text { skewed. However, they expose investors to substantial levels of market risk. After adjusting for } \\
\text { equity and bond factors, the Swap spread arbitrage and the Volatility Arbitrage strategies deliver } \\
\text { insignificant alphas. In contrast, some "intellectual capital" intensive strategies such as Yield curve } \\
\text { arbitrage, Mortgage arbitrage or Capital structure arbitrage produce significant alphas (even after } \\
\text { taking fees into consideration) }\end{array}$ \\
\hline Fund and Hsieh (1997) & Morningstar, 1991-1995 & $\begin{array}{l}\text { Bottom-Up/Regression based, } \\
\text { portfolio construction, PCA }\end{array}$ & $\begin{array}{l}\text { There are certain types of option strategies corresponding to specific strategies. There are five } \\
\text { dominant strategies: Systems/Opportunistic, Global/Macro, Value, Systems/Trend Following, and } \\
\text { Distressed. Beyond the "location" component of return they focus on "how the manager trades" and } \\
\text { leverage. Dynamic trading strategies can improve the performance of a traditional stock-bond } \\
\text { portfolio without substantially increasing its risk }\end{array}$ \\
\hline Fung and Hsieh (2001) & $\begin{array}{l}\text { FII, CME, Datastream, 1989- } \\
1997\end{array}$ & $\begin{array}{l}\text { Bottom-Up/Regression and } \\
\text { portfolio based }\end{array}$ & $\begin{array}{l}\text { Trend-following fund returns resemble lookback straddle returns. Trend followers or portfolios of } \\
\text { lookback straddles can reduce the volatility of a typical bond and stock portfolio during severe } \\
\text { market conditions. Trend-following funds do have systematic risk, although this risk cannot be } \\
\text { observed in the context of a linear model applied to standard asset benchmarks. In addition, during } \\
\text { stressful market conditions trend-following funds can reduce the volatility of a typical stock and } \\
\text { bond portfolio }\end{array}$ \\
\hline Fung and Hsieh (2002a) & $\begin{array}{l}\text { FII, CME, Datastream, 1989- } \\
2001\end{array}$ & $\begin{array}{l}\text { Bottom-Up/Regression and } \\
\text { portfolio based }\end{array}$ & $\begin{array}{l}\text { Trend followers mimic the pay-out of a lookback option on traditional assets. It is beneficial to use } \\
\text { asset-based style factors for modelling hedge funds. Hedge fund directional strategies can be } \\
\text { modelled with "long only" asset-based style factors (e.g. conventional indices). The "directional } \\
\text { component" can represent more than 50\% of the hedge fund return variation }\end{array}$ \\
\hline Fung and Hsieh (2004) & HFR, TASS, 1998-2002 & $\begin{array}{l}\text { Bottom-Up/Regression based, PCA, } \\
\text { and Kalman filter }\end{array}$ & $\begin{array}{l}\text { The proposed model of hedge funds returns is similar to arbitrage pricing theory models with } \\
\text { dynamic risk coefficients explaining up to } 80 \% \text { of monthly returns variation. Their seven ABS risk } \\
\text { factors are found in } 37 \% \text { of HFR hedge funds and } 57 \% \text { of those in the TASS database }\end{array}$ \\
\hline Huber and Kaiser (2004) & $\begin{array}{l}\text { S\&P Hedge Fund Indices, } \\
\text { 1998-2003 }\end{array}$ & $\begin{array}{l}\text { Bottom-Up/Regression based, } \\
\text { portfolio construction }\end{array}$ & $\begin{array}{l}\text { Hedge funds and CTAs using certain trading strategies generate returns similar to options. The } \\
\text { structures of CTAs have a payment profile similar to a long straddle. The Merger arbitrage strategy } \\
\text { can be determined with a short put option on the S\&P } 500 \text { index whereas the Managed futures } \\
\text { strategy can be determined by a long straddle in the S\&P } 500 \text { index }\end{array}$ \\
\hline
\end{tabular}


Table 3. Performance Attribution - Non-linear Studies

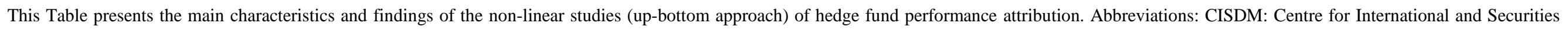

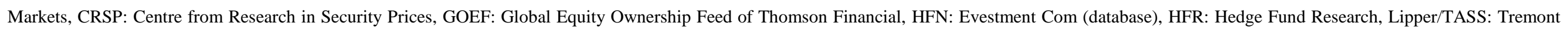

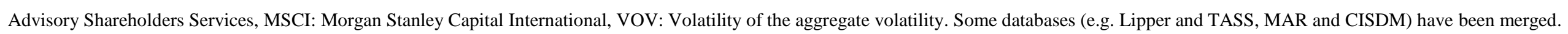

\begin{tabular}{|c|c|c|c|}
\hline Study & Sample & Approach/Methodolog & Findings \\
\hline $\begin{array}{l}\text { Agarwal, Arisoy, and } \\
\text { Naik (2016) }\end{array}$ & $\begin{array}{l}\text { Eurekahedge, HFR, } \\
\text { Lipper TASS, and } \\
\text { Morningstar, 2006-2012 }\end{array}$ & $\begin{array}{l}\text { Up-Bottom/Regression based, } \\
\text { portfolio construction }\end{array}$ & $\begin{array}{l}\text { Hedge funds have a significant negative VOV (volatility of aggregate volatility) exposure especially during financial } \\
\text { crises. Funds' VOV betas have a significant ability to predict excess returns one month ahead. Funds with low VOV } \\
\text { betas outperform funds with higher VOV betas during the financial crisis period. Strategies with more negative VOV } \\
\text { betas deliver superior returns when uncertainty in the market is less }\end{array}$ \\
\hline $\begin{array}{l}\text { Agarwal, Jiang, Tang, } \\
\text { and Yang (2013) }\end{array}$ & $\begin{array}{l}\text { SEC's EDGCAR } \\
\text { database, 1999-2007 }\end{array}$ & $\begin{array}{l}\text { Up-Bottom/Probit-Tobit model, } \\
\text { logistic regression, portfolio } \\
\text { construction }\end{array}$ & $\begin{array}{l}\text { There is evidence of managerial skill in stock picking. Funds running large risky portfolios with nonconventional } \\
\text { strategies pursue confidentiality frequently and confidential holdings exhibit superior performance up to } 12 \text { months. } \\
\text { Confidential treatment provides an incentive for active portfolio managers, whereas it relieves fund managers from } \\
\text { having to reveal their private information, not having exploited the full benefits yet }\end{array}$ \\
\hline Patton (2009) & HFR, TASS, 1993-2003 & $\begin{array}{l}\text { Up-Bottom/Regression based, } \\
\text { bootstrap methods }\end{array}$ & $\begin{array}{l}\text { About one quarter of funds in the market neutral category are significantly non-neutral. For other fund styles the } \\
\text { proportions of non-neutral funds are from } 50 \% \text { for fund of funds to } 85 \% \text { for equity non-hedge style. Market neutral } \\
\text { style funds are more neutral to market returns than other categories such as equity hedge, non-equity hedge, or event } \\
\text { driven funds }\end{array}$ \\
\hline $\begin{array}{l}\text { Avramov, Barras, and } \\
\text { Kosowski (2013) }\end{array}$ & $\begin{array}{l}\text { Barclayhedge, TASS, } \\
\text { HFR, CISDM, MSCI, } \\
\text { 1994-2008 }\end{array}$ & $\begin{array}{l}\text { Up/Bottom, Regression based, } \\
\text { portfolio construction }\end{array}$ & $\begin{array}{l}\text { Approximately } 63 \% \text { of the sample funds have expected returns that change according to business conditions. Out-of- } \\
\text { sample, a simple strategy that combines the fund's return forecasts obtained from individual investors produces superior } \\
\text { performance. A conditional (singe-predictor) strategy that forecasts each macro variable (and selecting the top decile of } \\
\text { funds with the highest return mean) is able to deliver superior performance. Another option is to diversify and use the } \\
\text { average forecast from each predictor that avoids a poor fund selection when there is no accuracy in the return } \\
\text { forecasting }\end{array}$ \\
\hline $\begin{array}{l}\text { Bali, Brown and } \\
\text { Caglayan (2011) }\end{array}$ & Lipper/TASS, 1994-2008 & $\begin{array}{l}\text { Up-Bottom/Cross-sectional } \\
\text { regressions, quintile portfolios }\end{array}$ & $\begin{array}{l}\text { There is a positive relationship between default risk premium and hedge fund future return. More specifically, funds } \\
\text { with higher exposure to the default risk premium in the previous month deliver higher returns in the following month. } \\
\text { Hedge funds with lower exposure to inflation deliver higher returns in the future. In particular, funds with lower } \\
\text { exposure to inflation in the previous month deliver higher returns in the following month }\end{array}$ \\
\hline $\begin{array}{l}\text { Bali, Brown and } \\
\text { Caglayan (2012) }\end{array}$ & $\begin{array}{l}\text { Lipper/TASS, } 1994 \text { to } \\
2010\end{array}$ & $\begin{array}{l}\text { Up-Down/Cross-sectional } \\
\text { regressions, portfolio analysis }\end{array}$ & $\begin{array}{l}\text { Systematic risk is more powerful than residual risk in predicting the cross-sectional variation in hedge funds even after } \\
\text { controlling for various fund characteristics (e.g. age, size and fees) and risk factors. Funds within the highest systematic } \\
\text { risk quintile generate } 6 \% \text { more average annual return compared to funds within the lowest risk quintile. The relationship } \\
\text { between residual risk and future fund returns is insignificant }\end{array}$ \\
\hline $\begin{array}{l}\text { Bali, Brown and } \\
\text { Caglayan (2014) }\end{array}$ & Lipper TASS, 1994-2012 & $\begin{array}{l}\text { Up-Bottom/Cross-sectional } \\
\text { regressions, portfolio analysis, } \\
\text { PCA }\end{array}$ & $\begin{array}{l}\text { There is a positive and significant relationship between uncertainty beta and hedge fund returns even when taking into } \\
\text { consideration fund characteristics and risk factors. Macroeconomic risk is a better determinant of hedge fund returns } \\
\text { than common financial risk factors. Directional strategies have a high exposure to the underlying macroeconomic risk } \\
\text { factors. Non-directional funds and mutual funds do not have significant macro-timing ability }\end{array}$ \\
\hline Brown (2012) & $\begin{array}{l}\text { HFN and HFR, 1997- } \\
2010\end{array}$ & $\begin{array}{l}\text { Up-Bottom/Stepwise } \\
\text { regressions }\end{array}$ & $\begin{array}{l}\text { For most hedge fund strategies, volatility is an important source of systematic risk. Volatility measures based on equity } \\
\text { market returns are more robust than volatility measures based on commodity market or fixed income. Many hedge fund } \\
\text { styles carry significant exposures to traditional systematic risk factors such as equities, interest rates or credit. There is } \\
\text { some evidence that fees may overwhelm hedge fund alpha }\end{array}$ \\
\hline $\begin{array}{l}\text { Chung, Fung, and Patel } \\
\text { (2015) }\end{array}$ & $\begin{array}{l}\text { GOEF, CRSP, French's } \\
\text { website, Orissa Group, } \\
\text { 1997-2006 }\end{array}$ & $\begin{array}{l}\text { Up-Bottom/Regression based, } \\
\text { cross-sectional regressions }\end{array}$ & $\begin{array}{l}\text { Hedge funds present stock-picking superiority for their loading on the market risk factor compared to other institutional } \\
\text { investors across three different market eras: bubble, deflation, and recovery. A high churn rate and a high active share } \\
\text { appear to be necessities for superior hedge fund returns. In addition, hedge funds load negatively on an illiquidity factor } \\
\text { compared to other institutional investors. The robust superiority of hedge funds aligns with the use of active information } \\
\text { acquisition (high churn rate) and active portfolio management (high active share) }\end{array}$ \\
\hline
\end{tabular}




\section{Table 3. Continued}

\begin{tabular}{|c|c|c|c|}
\hline $\begin{array}{l}\text { Hubner, Lambert and } \\
\text { Papageorgiou (2015) }\end{array}$ & HFR, 1996-2009 & $\begin{array}{l}\text { Up-Bottom/Higher moment } \\
\text { regression based }\end{array}$ & $\begin{array}{l}\text { The implied skewness and kurtosis of index portfolios increase models' explanatory power and reduce the specification } \\
\text { error for the majority of hedge fund strategies. Market neutral, Relative value, and Fund of funds styles change their } \\
\text { market exposure during financial crises. If fund managers use the volatility, skewness, and kurtosis implied by US } \\
\text { options as tools for anticipating market movements then they should adjust their market exposure according to these } \\
\text { movements }\end{array}$ \\
\hline $\begin{array}{l}\text { Ibbotson, Chen and Zhu } \\
\text { (2011) }\end{array}$ & TASS, 1995-2009 & Up-Bottom/Regression based & $\begin{array}{l}\text { Hedge funds have positive alphas even during the } 2008 \text { financial crisis. Their exposures are generally reduced during } \\
\text { bear markets. During the technology bubble collapse, fund managers on average underweighted equities in their } \\
\text { portfolios }\end{array}$ \\
\hline $\begin{array}{l}\text { Namvar, Phillips, } \\
\text { Pukthuanthong, and } \\
\text { Rau (2016) }\end{array}$ & $\begin{array}{l}\text { CISDM and TASS } \\
\text { Lipper, 1996-2010 }\end{array}$ & $\begin{array}{l}\text { Up-Bottom/PCA, time-series, } \\
\text { panel regression }\end{array}$ & $\begin{array}{l}\text { During weak market states skilled fund managers maintain low systematic risk via active adjustments to return factor } \\
\text { loadings even providing with low excess return. In strong market states, skilled fund managers provide incremental } \\
\text { higher alpha than low skilled managers through superior asset selection ability. Over a two-year period, only } 30 \% \text { of } \\
\text { funds remain in the same risk quintile. Systematic risk management skill is higher for better educated fund managers } \\
\text { and lower for fund managers who manage funds with poor performance, low investor flows, and greater performance } \\
\text { volatility }\end{array}$ \\
\hline $\begin{array}{l}\text { Patton and Ramadorai } \\
\text { (2013) }\end{array}$ & $\begin{array}{l}\text { HFR, CISDM, TASS, } \\
\text { Morningstar and Barclay, } \\
\text { 1994-2009 }\end{array}$ & $\begin{array}{l}\text { Up-Bottom/Dynamic high } \\
\text { frequency econometrics }\end{array}$ & $\begin{array}{l}\text { Hedge fund risk exposures change across and within months. Exposure variation is higher early in the month and then } \\
\text { gets progressively lower until the reporting date. There are changes to portfolio allocations and to exposures in different } \\
\text { asset classes, however changes in portfolio allocations are the main drivers of the funds' risk exposure variation. Also, } \\
\text { hedge funds update their positions at a higher frequency than mutual funds }\end{array}$ \\
\hline $\begin{array}{l}\text { Racicot and Theoret } \\
\text { (2016) }\end{array}$ & $\begin{array}{l}\text { Greenwich Alternative } \\
\text { Investment, 1995-2012 }\end{array}$ & $\begin{array}{l}\text { Up-Bottom/Kalman filter, time- } \\
\text { series and cross-sectional } \\
\text { regressions }\end{array}$ & $\begin{array}{l}\text { The macroeconomic uncertainty is relied on conditional variances of six macro and financial variables (growth on } \\
\text { industrial production, interest rate, inflation, market return, growth of consumer credit, and the term spread). Hedge } \\
\text { funds' market beta reduces with macro uncertainty. This makes their strategies more homogeneous, resulting in a } \\
\text { contribution to increased systematic risk in the financial system. The dispersion of hedge funds returns and alphas } \\
\text { increases during times of rising macroeconomic uncertainty }\end{array}$ \\
\hline Slavutskaya (2013) & $\begin{array}{l}\text { TASS, HFR, CISDM, } \\
\text { Altvest, 1994-2009 }\end{array}$ & $\begin{array}{l}\text { Up-Bottom/Cross-sectional and } \\
\text { time-series regressions }\end{array}$ & $\begin{array}{l}\text { By combining cross-sectional and time-series information there is an improvement in the out-of-sample accuracy of the } \\
\text { linear factor model. The root mean squared prediction error in panel data models is significantly smaller }(10 \%-15 \%) \\
\text { than linear regressions. The "naïve shrinkage" beta estimates correspond to weighted averages of individual fund and } \\
\text { mean strategy betas }\end{array}$ \\
\hline
\end{tabular}




\section{Table 4. Performance Attribution - Non-linear Studies}

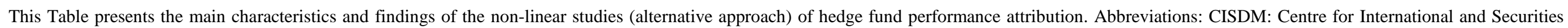

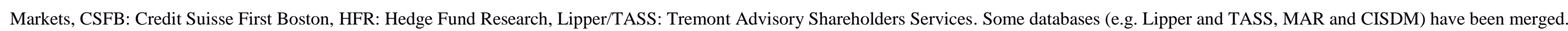

\begin{tabular}{|c|c|c|c|}
\hline Study & Sample & Approach/Methodology & Findings \\
\hline $\begin{array}{l}\text { Akay, Senyuz, and Yoldas } \\
\text { (2013) }\end{array}$ & $\begin{array}{l}\text { Dow Jones Credit Suisse } \\
\text { Hedge Fund Indices, 1994- } \\
2010\end{array}$ & $\begin{array}{l}\text { Alternative/Markov regime } \\
\text { switching model }\end{array}$ & $\begin{array}{l}\text { There are three regimes that describe hedge fund returns. When accounting for common risk factors, } \\
\text { there is hedge fund return co-movement across different time periods. When considering common risk } \\
\text { factors, the co-movement in hedge fund returns is not limited to periods of extreme financial turmoil. } \\
\text { The TED spread (margin requirement on the S\&P } 500 \text { contract) and the VIX index play a significant } \\
\text { role in leading to contagion in hedge fund returns }\end{array}$ \\
\hline $\begin{array}{l}\text { Billio, Getmansky and } \\
\text { Pelizzon (2012) }\end{array}$ & CSBF/Tremont, 1994-2009 & $\begin{array}{l}\text { Alternative/Regime switching } \\
\text { models }\end{array}$ & $\begin{array}{l}\text { Beyond market exposure, hedge funds have non-linear exposures to liquidity, volatility, credit, term } \\
\text { spread, and commodities. Hedge funds change their exposures when dealing with different regimes. } \\
\text { Hedge fund exposures depend on whether the equity market is in the up, down or tranquil regime }\end{array}$ \\
\hline Bollen, and Whaley (2009) & CISDM, 1994-2005 & $\begin{array}{l}\text { Alternative/Optimal change-point } \\
\text { regression }\end{array}$ & $\begin{array}{l}\text { Through change-point regression (allowing for a single shift in parameters for each fund), there are } \\
\text { significant changes in risk factor parameters in about } 40 \% \text { of the sample hedge funds. For live funds, } \\
\text { switches tend to occur early in the fund's life whereas switcher funds tend to outperform non-switcher } \\
\text { funds }\end{array}$ \\
\hline Giannikis and Vrontos (2011) & HFR, 1990-2009 & $\begin{array}{l}\text { Alternative/Threshold regression } \\
\text { with Bayesian approach }\end{array}$ & $\begin{array}{l}\text { Different hedge fund strategies exhibit non-linear relations to different risk factors. A Bayesian } \\
\text { approach improves hedge fund performance appraisal. Different hedge fund strategies exhibit different } \\
\text { timing abilities }\end{array}$ \\
\hline Jawadi and Khanniche (2012) & CSFB/Tremont, 1994-2009 & $\begin{array}{l}\text { Alternative/Smooth transition } \\
\text { regression }\end{array}$ & $\begin{array}{l}\text { Hedge funds returns change and differ asymmetrically during different financial conditions. Hedge } \\
\text { fund exposures vary over time according to strategy and regime. Also, the relationship between hedge } \\
\text { fund returns and risk factors varies over time and depends on regimes (e.g. expansion, crisis) }\end{array}$ \\
\hline $\begin{array}{l}\text { O’Doherty, Savin, and Tiwari } \\
\text { (2015) }\end{array}$ & Lipper/TASS, 1994-2011 & $\begin{array}{l}\text { Alternative/Pooled benchmark } \\
\text { model approach, portfolio } \\
\text { construction }\end{array}$ & $\begin{array}{l}\text { By using the pooled benchmark approach, there is a reduction in the (benchmark) error of the factor- } \\
\text { based attribution models. The model pooling approach has more predictive power for failures among } \\
\text { sample funds than other performance attribution models }\end{array}$ \\
\hline
\end{tabular}


${ }^{1}$ Although some of the older papers will be well known to hedge fund researchers, it is important to include some key studies so as to analyse their influence on newer studies.

${ }^{2}$ The four named models cover all hedge fund strategies and refer to the category of relative price models.

${ }^{3}$ These include, for example, market value or equity capitalization size proposed by Banz (1981) and Reinganum (1981), and earnings-to-price ratio proposed by Basu (1983). Other examples are leverage, mentioned by Bhandari (1988) and stock liquidity as mentioned by Amihud (2002).

${ }^{4}$ In the appendix, Table 1 provides the discussed studies to help the reader's understanding.

${ }^{5}$ In general, non-linear models are used to explain hedge fund returns because, either, the observation frequency is different from trading frequency, or, the assets being held are non-linear functions of some primitive factors. Regarding the first case, one can replicate returns to option prices via dynamic trading. Replicated portfolio's return is locally linear in the underlying factors, however if, for instance, monthly returns are used to evaluate the performance of the portfolio, the return will be non-linear in terms of returns on the underlying assets due to the fact that observation frequency is much longer than the trading frequency. Concerning the second case, when a fund follows a buy and hold strategy, the returns will be linear functions of its underlying assets regardless of whether monthly or annual observations are used. Nevertheless, the returns will be non-linear in terms of some primitive factors that underlie the assets being held. Usually, these two effects are indistinguishable. For instance, explanatory powers of Fung and Hsieh factors could be the result of dynamic trading by funds and their holdings of long and short positions in options or that we do not have daily returns on funds (we thank the anonymous referee for this comment)

${ }^{6}$ The return of any portfolio is a linear average of the returns of its assets. However, the definition of a (non-) linear model is not an easy task because the term linear can be interpreted into different ways. First, it may be the linearity in variables, although if the independent variable appears with a power 2 then it can be interpreted as a non-linear function. Second, it may be the linearity in parameters, although it may or may not be linear in the independent variable(s), thus being a linear (in the parameters) regression model. Third, it may be the case that the linearity between the dependant and independent variables changes over time. A model with structural breaks can be regarded (as a whole) as a non-linear model.

${ }^{7}$ In the appendix, Table 2, 3 and 4 provide the discussed bottom-up, up-bottom, and alternative approach studies, respectively.

${ }^{8} \mathrm{~A}$ lookback straddle is an option strategy that is a combination of a lookback call plus a lookback put (options that are traded in Over-The-Counter markets). The first component grants the holder the right but not the obligation to buy an asset at the lowest price identified during the lifetime of the option. The second component grants the holder the right but not the obligation to sell an asset at the highest price observed during the lifetime of the option.

${ }^{9}$ A long straddle is a combination of a long call and a long put with the same strike price.

${ }^{10}$ These are: Systems/Opportunistic, Global/Macro, Value, Systems/Trend Following, and Distressed.

${ }^{11}$ There are more studies that are based on the same initial ABS-creation mechanism, describing other strategies (these are not discussed for space reasons). For example, Mitchel and Pulvino (2001), Fund and Hsieh (2002b) and Fung and Hsieh (2000c) developed factors for the risk arbitrage, convergence traders and long-short equity funds, respectively. 